\title{
Incorporating a water-logging routine into CERES-Maize, and some preliminary evaluations
}

\author{
AS du Toit ${ }^{1 *}$, MA Prinsloo', BM Wafula ${ }^{2}$ and PK Thornton ${ }^{3}$ \\ 1 ARC-Grain Crops Institute, P/bag X 1251, Potchefstroom, 2520 South Africa \\ 2 Kenya Agricultural Research Institute (KARI), PO Box 1230, Machakos, Kenya \\ 3 International Livestock Research Institute (ILRI), PO Box 30709, Nairobi, Kenya
}

\begin{abstract}
The inability of CERES-Maize v3.0 to simulate a fluctuating water table has been identified as a major constraint in using this particular model in South Africa and in Kenya. Information regarding fluctuating water tables under specific conditions, and their influence on maize production, has been presented in South African literature. The objective of this study was to construct a simple water-logging subroutine based on these mechanisms, using the existing input data structure of CERES-Maize. Results indicate that it is possible to simulate the impact of water logging on maize plants in this way. Further studies are needed to evaluate the assumptions made in this study and, if necessary, to make some refinements to the water-logging subroutine.
\end{abstract}

\section{Introduction}

In recent years it has become increasingly difficult to increase agricultural production by means of current methods of information transfer (Uehara, 1998). Most field trials conducted over the past decade have been aimed at refinement of recommendations made to the producer. It may be possible to stabilise African maize production if recommendations can be tailored to particular soil, plant and climatic conditions. In this respect the use of simulation models may serve to improve recommendations pertaining to variety selection, fertiliser use, irrigation scheduling, and optimum planting times (Acock, 1982; Thornton, 1990; Piper and Weiss, 1990).

The CERES-Maize model may be used for management decision making by the producer, provided that the model is evaluated and calibrated for various regions (Ritchie et al., 1998). This is an internationally-recognised maize model, highly acclaimed by researchers in the field (De Vos and Mallett, 1987; Du Pisani, 1987; Carberry et al., 1989; Piper and Weiss, 1990). The model was designed to use a minimum set of soil, weather, genetic and management information. It is a daily-incrementing model and therefore requires daily weather data consisting of maximum and minimum temperature, solar radiation and rainfall. It calculates crop phasic and morphological development using temperature, day length and genetic characteristics. Leaf area index, plant population and row width provide information for determining the amount of light interception, which is assumed to be proportional to biomass production. The biomass is partitioned into the various plant parts by means of a priority system. Water and nitrogen balance submodels provide feedback that influences the development of growth processes.

During a project to develop an integrated approach to assessing soil fertility and climatic interactions in pilot maize-producing

\footnotetext{
* To whom all correspondence should be addressed.

푱 018 2996249; fax: 018 2947146; e-mail: Andre@Igg2.agric.za Received 4 January 2002; accepted in revised form 11 May 2002.
}

areas in Kenya, it became evident that CERES-Maize v3.0 could not simulate the impact of water logging on maize growth (a relatively common occurrence in certain parts of Kenya), a conclusion supported by Hensley et al. (1997) and Hensley (2000).

Hensley et al. (1997) and Hensley (2000) describe the watertable logic for sandy soils as follows. There is an upward linear decrease in water content from the water table, where the soil water is at saturation, to the drained upper limit (DUL) of the layer approximately $600 \mathrm{~mm}$ above the water table. If the water-table depth is less than about $600 \mathrm{~mm}$ from the soil surface, aeration stress occurs for maize with a consequent decrease in yield. It can be expected that the number of live roots will decrease with an increase in time of water logging, and thus the uptake of nutrients will also decrease.

The objective of this study was to incorporate the Hensley logic into the water uptake and drainage subroutines of CERES-Maize. It simulates the rise and fall of the water table, with the concomitant effects of water logging on the growth of the maize plant.

\section{Material and methods}

\section{Crop growth simulation model}

The CERES models for maize, sorghum, wheat, millet and barley were combined to provide a generic multi-crop model which runs with a single set of code, incorporating the development and growth sections for each individual model into a single module with a single soil component (Tsuji et al., 1994; Ritchie et al., 1998). According to Ritchie (1991), generic models should allow users to have more uniform procedures for validating models and for linking with components not included in the generic model. The generic CERES-Maize model (Hoogenboom et al., 1994), with modifications made by Du Toit (1996) to simulate secondary ears and tillering under low plant populations, was used for the simulations. An experimental approach to water-table simulation was used to simulate the results as reported in Hensley et al (1997). The results reported as "without water-table simulation" in this paper do not include the experimental approach. 


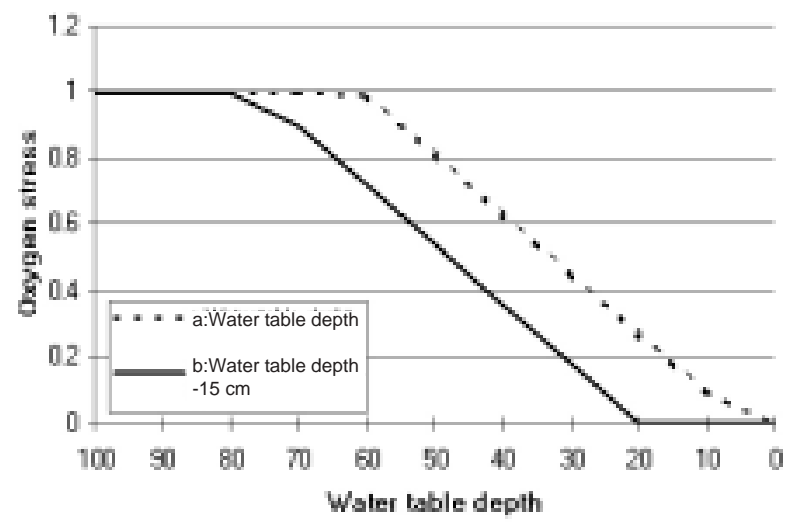

Figure 1

The relationship between water-table depth and oxygen stress
Witer table simulation

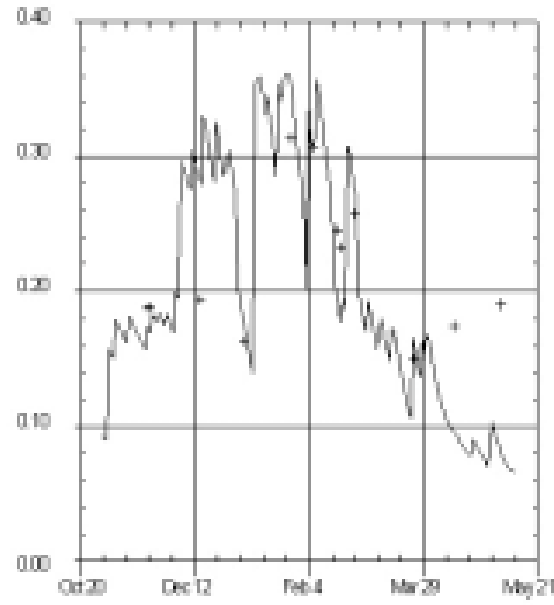

Nowater table simulation

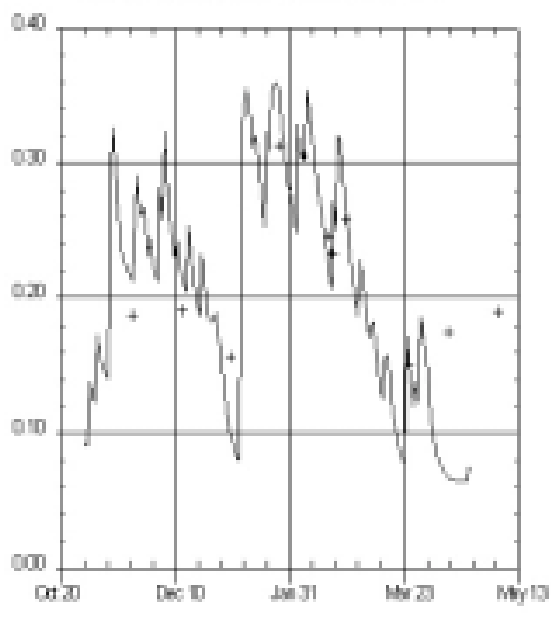

$0-20 \mathrm{~cm}$
Figure 2

Measured (+) and simulated (-) volumetric soil-water content over time for the "with" and "without" water-table simulation for the 0 to $20 \mathrm{~cm}$ soil layer
Veter table simulation

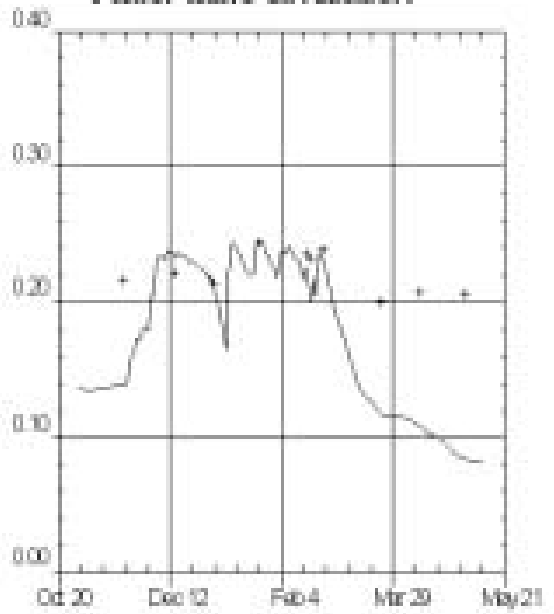

\section{Nowater table simulation}

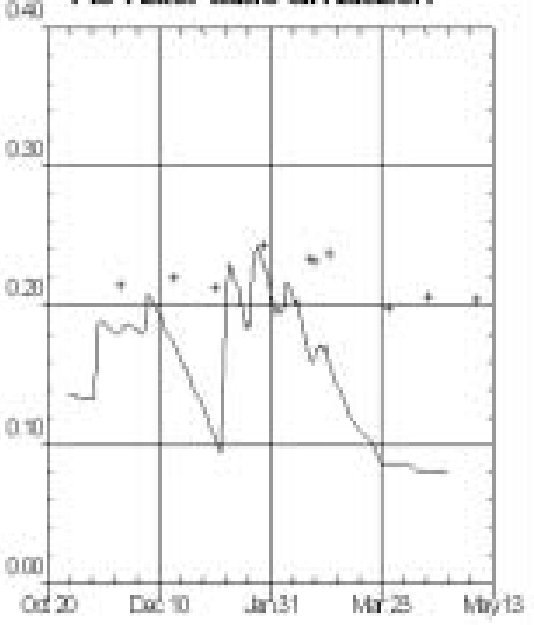

\section{$20-40 \mathrm{~cm}$}

Figure 3

Measured (+) and simulated (-) volumetric soil-water content over time for the "with" and "without" water-table simulation for the 20 to $40 \mathrm{~cm}$ soil layer

\section{Model modifications}

The subroutine of CERES-Maize that simulates the draining of soil water (DRAINE.FOR) was modified to simulate the fluctuation of the water table and to calculate the oxygen stress index (OSTRESS). The following modifications where made to DRAINE.FOR. For CERES to identify if a specific soil has a tendency to form a water table or not, the saturation of the first soil layer, SAT(1), needs to be set to 0.40 as a volume fraction and the total drainage rate to 0.001 fraction $\cdot \mathrm{d}^{-1}$. If either of these values are not met, no water-table simulation will occur. If the soil-water content of the first layer, SW(1), exceeds the drained upper limit of the same layer, DUL(1), all available water above DUL(1) will then drain (VLOEI) to the second layer. This is then repeated for consecutive layers, according to the "tipping bucket" concept of soil water modelling (Ritchie, 1998). In order for CERES to identify the depth of the water table (WTDIEP), the soilwater content of a specific layer, SW(L), needs to be greater or equal to SAT(L)-0.02. VLOEI is then changed from volume to a volumetric measurement by defining it with the soil depth and adding it to the soil-water content of the layer directly above the water table. If this layer SW(L) exceeds SAT(L)0.02 , it will become the WTDIEP and the process is repeated. If WTDIEP is less than or equal to $600 \mathrm{~mm}$, oxygen stress OSTRESS is calculated as follows:

$$
\begin{aligned}
\text { OSTRESS }= & 1.0-(\text { AMIN1 }(1.0,(1.09 \\
& -0.018 *(\text { WTDIEP-15) })))
\end{aligned}
$$

AMIN1 is a Fortran 90 command - selecting the smallest value. The development Function 1 will be discussed later in this paper. In the growth subroutine GROSUB, OSTRESS was added to water and nitrogen stress to decrease growth. The source code for the modified DRAINE.FOR subroutine is shown in Appendix 1. 


\section{Results and discussion}

Hensley et al. (1997) stated that if the water-table level rises above a soil depth of $600 \mathrm{~mm}$, water logging would occur. To quantify OSTRESS, the assumption was made that at $600 \mathrm{~mm}$ depth no stress occurs, while increased stress will occur with each rising increment of the water table above 600 mm until complete saturation, and hence maximum stress occurs when the water-table level reaches the soil surface. Linear regression was therefore drawn between these two points.

In GROSUB no stress is indicated by a value of 1 and full stress by 0 ; to use the same principle, the linear function was subtracted from unity. Because of an oxygen deficiency all roots can be expected to die in the soil layer just above the water table. Figure 1 indicates the influence of the water-table depth on oxygen stress without taking into account root die-back because of the influence on oxygen stress in the layer above the water table. To include this, $150 \mathrm{~mm}$ is subtracted from the water-table depth, as indicated in Function b of Fig. 1. This reaction to oxygen stress is simulated in the partially saturated soil above the water table. For this study a water-table depth is defined as the soil layer closest to the soil surface that is saturated. Further study is needed to find the correct function and to verify the different assumptions made in this study.

In the 0 to $200 \mathrm{~mm}$ layer (Fig. 2) the simulation line of the water table follows the same trends as the measured values $(+)$. The point at 12 December indicates a marginal increase in soil-water content while the simulation shows a significant increase. This could possibly be explained by saying that the subsoil was not saturated at this stage. When the subsoil becomes saturated, the simulation accuracy increases.

At the end of the growing season the measured values increased while the simulated values decreased; this tendency appears in all the different layers (Figs. 3 to 7). One possible explanation is that CERES-Maize is over-predicting maturity and thus is still simulating water uptake even though measured soil-water content indicates that water uptake by the plant has stopped. The influence of water logging on the grain-filling period is in need of further study.

The degree of water saturation within a waterlogged soil is determined by the porosity which, in turn is related to the bulk density. In general it is calculated as 1-(bulk density/particle density) where mean particle density is assumed to be $2.65 \mathrm{~g} \cdot \mathrm{cm}^{-3}$. A volumetric water content of 0.40 will therefore be related to a bulk density of $1.60 \mathrm{~g} \cdot \mathrm{cm}^{-3}$. The particular E-horizon $(500-700 \mathrm{~mm})$ had a bulk density of $1.90 \mathrm{~g} \cdot \mathrm{cm}^{-3}$, a volumetric drained upper limit value of 0.20 and a saturation value of 0.28 (Hensley et al., 1997). The water content of the Ehorizon was most of the time for the season in the region of 0.24 volumetric content, indicating the highly saturated state and the subsequent waterlogging effect on the maize plant.

Water table simuation

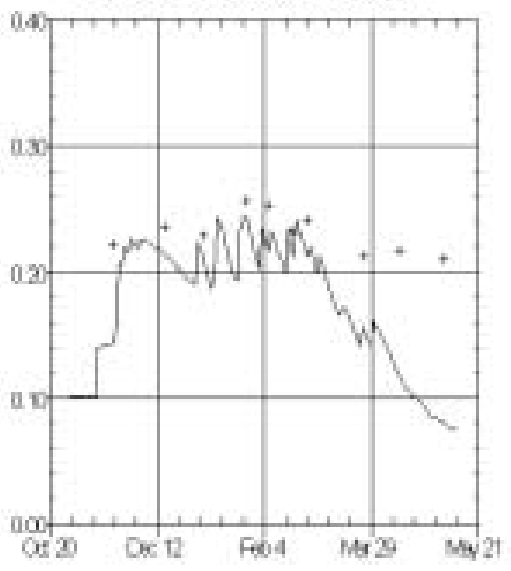

No water table simuation

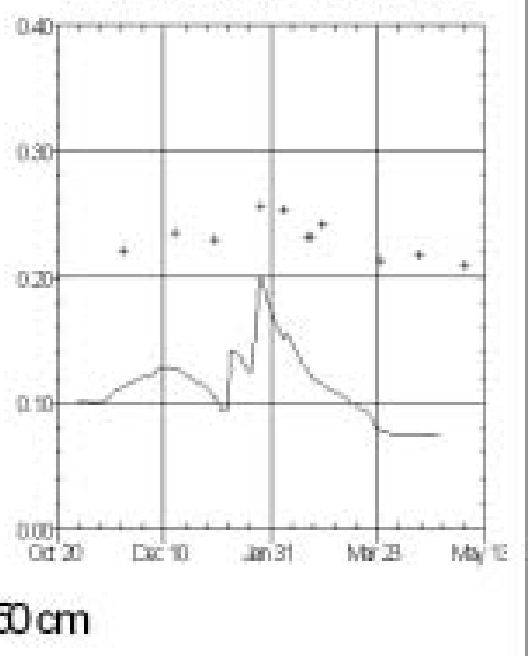

Figure 4

Measured (+) and simulated (-) volumetric soil-water content over time for the "with" and "without" water table simulation for the 40 to $50 \mathrm{~cm}$ soil layer

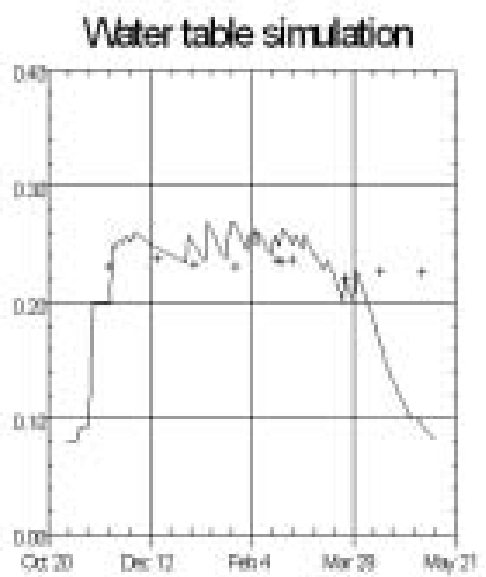

Nb water table simulation

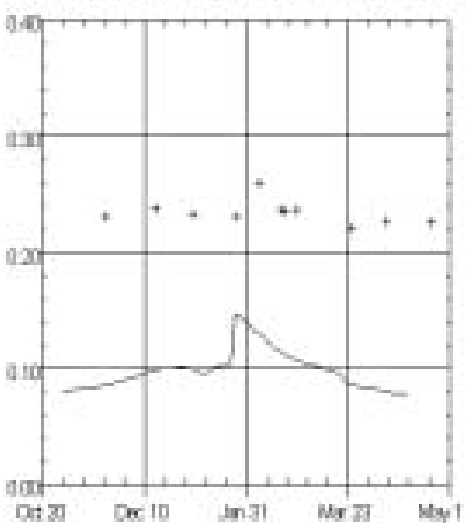

$50-70 \mathrm{~cm}$

Figure 5

Measured (+) and simulated (-) volumetric soil-water content over time for the "with" and "without" water table simulation for the 50 to $70 \mathrm{~cm}$ soil layer

Water table simulation

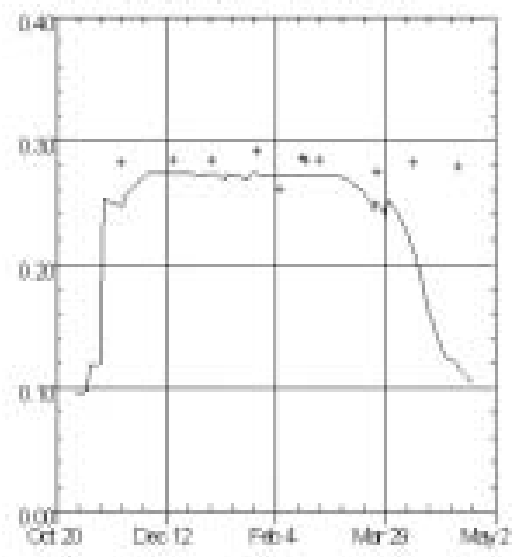

No water table simulation

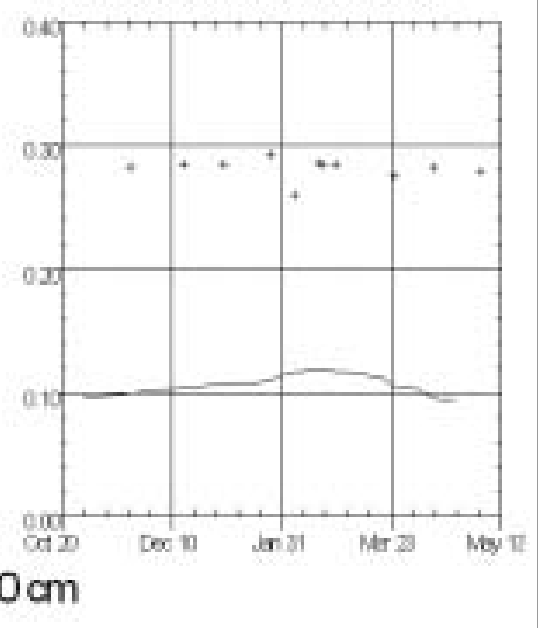

Figure 6

Measured (+) and simulated (-) volumetric soil-water content over time for the "with" and "without" water table simulation for the 70 to $90 \mathrm{~cm}$ soil layer 
Water table simulation

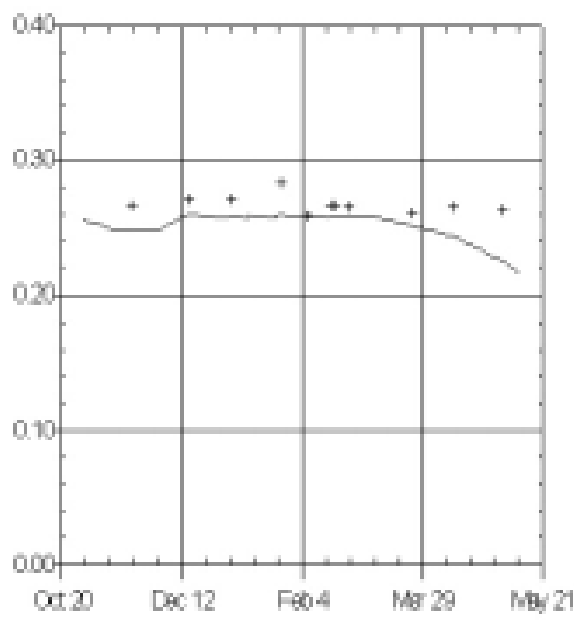

No water table simulation

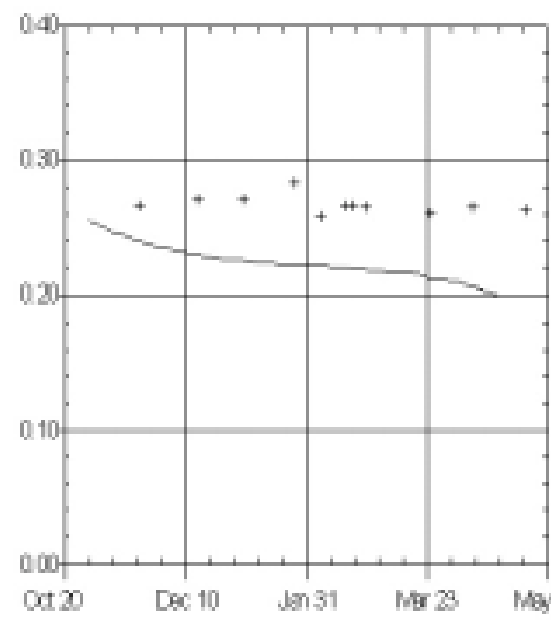

Figure 7

Measured (+) and simulated (-) volumetric soil-water content over time for the "with" and "without" water table simulation for the 90 to $120 \mathrm{~cm}$ soil layer

\section{$90-120 \mathrm{~cm}$}

The measured yield for this trial ranging from 0 to $2554 \mathrm{~kg} \cdot \mathrm{ha}^{-1}$ with a simulated yield of $7600 \mathrm{~kg} \cdot \mathrm{ha}^{-1}$ that does not consider the effect of saturation, therefore simulating normal drainage. When the influence of oxygen stress (OSTRESS) was included, the simulated yield decreased to $2480 \mathrm{~kg} \cdot \mathrm{ha}^{-1}$ to give a much more realistic yield simulation.

A version of CERES-Maize v3.1 has now been released that has the ability to simulate tile drainage (Garrison et al., 1999). For the model to simulate water logging, the soil-input file has been modified to include depth and saturation values for each of the soil profile layers. While this information is available for this profile, it is lacking for the Kenya soils.

\section{Conclusions}

When the water table is less than $600 \mathrm{~mm}$ from the soil surface, oxygen stress has an influence on biomass production and it can have just as devastating an influence on maize yield production as water and nitrogen stress. With the simulation of water logging it is possible to quantify the influence of oxygen stress on maize yield production.

The advantage of this work is that it is now possible to simulate the fluctuation of the water table without additional soil inputs. It must be kept in mind that the DRAIN.FOR subroutine was extended only to accommodate an average saturated volumetric content of 0.40 (at an average bulk density of $1.60 \mathrm{~g} \cdot \mathrm{cm}^{-3}$ ). Although no provision was made to accommodate a series of saturation values, the empirical approach used showed significant improvement of yield simulation in water-logged soils. If high-quality soil input data are available, the more mechanistic approach to water-table simulation as represented in CERES-Maize v3.1 would be the preferred approach. However, if such data are not available, this more empirical water simulation could be used, and both approaches should be complementary to each other, depending on the quantity of available soil information.

The influence of oxygen stress on the kernel growth period needs to be investigated to improve the simulation of maize growth and development under water-logging conditions. With the development phase of the project completed the modified DRAINE.FOR subroutine needs to be validated against independent water-logging maize trials. The lack of such trials with high quality data is a constraint and trials that fit these criteria need to be executed.

\section{Acknowledgements}

This research was carried out as part of the project "An integrated approach to assessing soil fertility and climatic interactions in pilot maize producing areas of Kenya". We are very grateful to John Lynam and the Rockefeller Foundation, Nairobi, for financial support, Joel Ransom for logistical support and the Ecoregional fund for continuing support on water-table simulation research.

\section{References}

ACOCK B (1982) A Proposal for the Role of Agricultural Systems Research Institute in Co-ordinating Modelling in the USDA-ARS and Delivering the Results to the Farmers and other End Users. USDAARS, Mississippi State.

CARBERRY P S, MUCHOW R E and MCCOWN, R L (1989) Testing the CERES-Maize simulation model in a semi-arid tropical environment. Field Crops Res. 20 297-315.

DE VOS RN and MALLETT J (1987) Preliminary evaluation of two maize (Zea Mays L.) growth-simulation models. S. Afr. J. Plant Soil 4 131-135.

DU PISANI AL (1987) The CERES-Maize model as a potential tool for drought assessment in South Africa. Water SA 13 (3) 159-163.

DU TOIT AS (1996) The Quantification of the Compensation Ability of the Maize Plant. Ph.D. Thesis, Dept. of Agronomy, Faculty of Agriculture, Univ. of the Free State, South Africa.

GARRISON MV, BATCHELOR WD, KANWAR RS and RITCHIE JT (1999) Validation of the CERES-Maize water and nitrogen balances under tile drainage conditions. Agric. Syst. 62 189-200.

HENSLEY M, ANDERSON JJ, BOTHA JJ, VAN STANDEN PP, SINGELS A, PRINSLOO M and DU TOIT A (1997) Modelling the Water Balance on Benchmark Ecotopes. Report to Water Research Commission by the ARC-Institute for Soil, Climate and Water. WRC Project No K5/508.

HENSLEY M (2000) Water tables and maize production In: Durand W and $\mathrm{du}$ Toit, AS (eds.) Proc. of Highveld Ecoregion Workshop. Potchefstroom, South Africa, 21-23 June 1999. 67 pp.

HOOGENBOOM G, JONES JW, WILKENS PW, BATCHELOR WD, BOWEN WT, HUNT LA, PICKERING NB, SINGH U, GODWIN DC, BAER B, BOOTE KJ, RITCHIE JT and WHITE JW (1994) Crop models. In: Tsuji GY, Uehara G and Balas S (eds.) DSSAT3. Vol. 22. Univ. of Hawaii, Honolulu, Hawaii.

PIPER EL and WEISS A (1990) Evaluation of CERES-Maize for reduction in plant population on leaf area during the growing season. Agric. Systems 33 199-213.

RITCHIE JT (1991) Specifications in the ideal model for predicting crop yields. In: Muchow RC and Bellamy JA (eds.) Climatic Risk in Crop 
Production: Models and Management for the Semi-Arid Tropics and Sub Tropics. CAB International, Wallingford, UK. 97-122.

RITCHIE JT (1998) Soil water balance and plant water stress. In: Tsuji G Y, Hoogenboom G and Thornton P K (eds.) Understanding Optionsfor Agricultural Production. Kluwer Academic Publishers, Dordrecht, The Netherlands. 41-54.

RITCHIE JT, SINGH U, GODWIN DC and BOWEN WT (1998) Cereal growth, development and yield. In: Tsuji GY, Hoogenboom G and Thornton PK (eds.) Understanding Options for Agricultural Production. Kluwer Academic Publishers, Dordrecht, The Netherlands. 79-98.

TSUJIGY, JONES JW, HOOGENBOOM G, HUNT LA and THORNTON PK (1994) Introduction. In: Tsuji GY, Uehara G and Balas S (eds.) DSSAT3. Vol. 1-1. University of Hawaii, Honolulu, Hawaii
THORNTON PK (1990) Application of Crop Simulation Models in Agricultural Research and Development in the Tropics and Subtropics. General Publication IFDC-G1, International Fertilizer Development Centre, Muscle Shoals, Alabama.

UEHARA G (1998) Synthesis. In: Tsuji GJ, Hoogenboom G and Thornton PK (eds.) Understanding Options for Agricultural Production. Kluwer Academic Publishers, Dordrecht, The Netherlands. 389-392.

WAFULA BM, THORNTON PK, DU TOIT AS and RANSOM JK (1998) An Integrated Approach to Assessing Soils Fertility and Climatic Interactions in Pilot Maize-Producing Areas of Kenya. Final Report submitted to the Rockefeller Foundation and KARI. 101 pp.

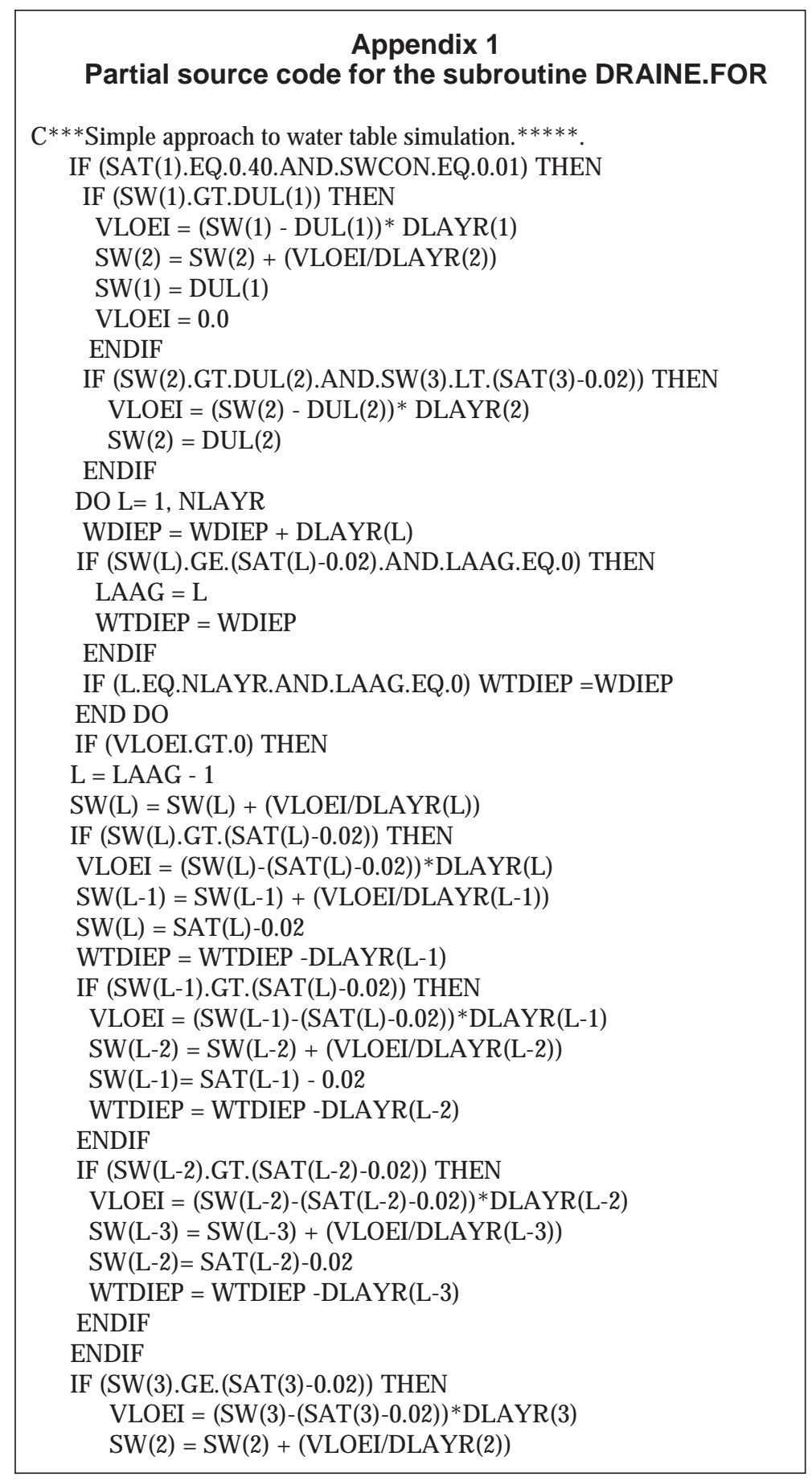




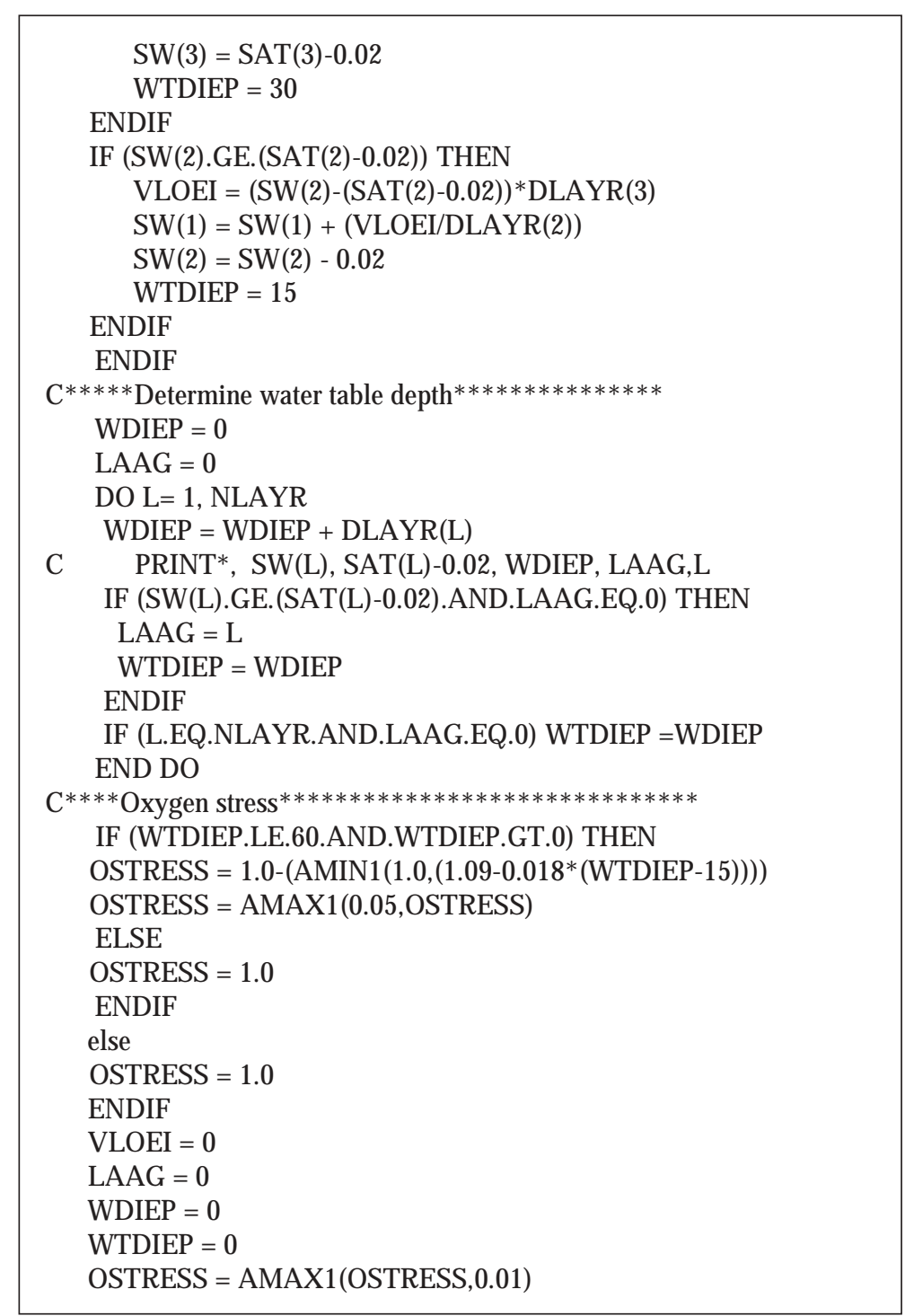

